\title{
Mobile Phones: A Trade-off between Speech Intelligibility and Exposure to Noise Levels and to Radio-Frequency Electromagnetic Fields
}

\author{
Arno Thielens ${ }^{\mathrm{a}, \mathrm{b},{ }^{*}}$, Annelies Bockstael ${ }^{\mathrm{a}, \mathrm{c}}$, Sofie Declerck ${ }^{\mathrm{a}}$, Reza Aminzadeh ${ }^{\mathrm{a}}$, Sam Aerts ${ }^{\mathrm{a}}$, \\ Dick Botteldooren $^{\mathrm{a}}$, Luc Martens ${ }^{\mathrm{a}}$ and Wout Joseph ${ }^{\mathrm{a}}$ \\ a Department of Information Technology, Ghent University/iMinds, Technologiepark 126, \\ Ghent B-9052, Belgium \\ ${ }^{\mathrm{b}}$ Berkeley Wireless Research Center, Department of Electrical Engineering and Computer \\ Sciences, University of California, Berkeley, 2108 Allston Way, Suite 200, Berkeley, CA \\ 94704, United States of America \\ ${ }^{c}$ École d'orthophonie et d'audiologie, Université de Montréal,7077 Av du Parc, Montréal, QC \\ H3N1X7, Canada \\ *Corresponding author: Arno Thielens, arno.thielens@ugent.be
}

Keywords: RF EM-Exposure, mobile phone, sound, specific absorption rate, speech intelligibility

\begin{abstract}
When making phone calls, cellphone and smartphone users are exposed to radio-frequency (RF) electromagnetic fields (EMFs) and sound pressure simultaneously. Speech intelligibility during mobile phone calls is related to the sound pressure level of speech relative to potential background sounds and also to the RF-EMF exposure, since the signal quality is correlated with the RF-EMF strength. Additionally, speech intelligibility, sound pressure level, and exposure to RF-EMFs are dependent on how the call is made (on speaker, held at the ear, or with headsets). The relationship between speech intelligibility, sound exposure, and exposure to RF-EMFs is determined in this study. To this aim, the transmitted RF-EMF power was recorded during phone calls made by 53 subjects in three different, controlled exposure scenarios: calling with the phone at the ear, calling in speaker-mode, and calling with a headset. This emitted power is directly proportional to the exposure to RF EMFs and is translated into specific absorption rate using numerical simulations. Simultaneously, sound pressure levels have been recorded and speech intelligibility has been assessed during each phone call. The results show that exposure to RF-EMFs, quantified as the specific absorption in the head, will be reduced when speaker-mode or a headset is used, in comparison to calling next to the ear. Additionally, personal exposure to sound pressure is also found to be highest in the condition where the phone is held next to the ear. On the other hand, speech perception is found to be the best when calling with a phone next to the ear in comparison to the other studied conditions, when background noise is present.
\end{abstract}

\section{Introduction}

Smartphones are nowadays commonly used for communication and entertainment. In order to enable a majority of their functionalities, these devices communicate wirelessly with a 
network. To this aim, they emit radio-frequency (RF) electromagnetic fields (EMFs) using antennas that are incorporated in the device. On the one hand, these EMFs are emitted by mobile devices (uplink) and on the other hand by the wireless network infrastructure (downlink). RF radiation can be absorbed in dielectric tissue, such as the tissues that make up the human body. This absorption is commonly quantified using the specific absorption rate (SAR). In order to prevent excessive tissue heating, the SAR is limited by international guidelines (ICNIRP, 1998) and international standards exist in order to assess the SARcompliance of smartphones (IEC, 2001). Every smartphone that is sold on the market has to be certified in this way. Consequently, there are a large number of SAR values available for a given emitted power (TX power) of smartphones. The SAR values obtained using these standardized tests are intended to be conservative estimates of the maximum potential SAR during phone usage, but provide no insight in the variations in SAR that might occur during actual use. Several studies have demonstrated that this SAR will depend on several subjectspecific factors. The actual SAR will depend on the type of phone and used antenna (Gosselin et al., 2011; Kühn, et al. 2013b), the morphology of the subjects' head (Adibzadeh et al., 2015), the age-dependent tissue properties of the subjects' bodies (Christ et al., 2010; Gosselin et al., 2011), the phone position and tilt next to the head (Ghanmi et al., 2014), the shape and posture of the hand holding the mobile phone ( $\mathrm{Li}$ et al., 2012), the used applications such as browsing or streaming video (Joseph et al. 2010), the used simulation software to determine a mobile phone's SAR (Siegbahn et al., 2010), and off course the power emitted by the phone (Kühn and Küster, 2013a).

SAR data are not representative for personal exposure if the associated emitted power of the phone is unknown (Kühn and Küster, 2013a). There are previous studies that registered transmitted (TX) powers during smartphone usage by a real subject. These TX data are available to the network operators (Lonn et al., 2004; Gati et al., 2010; Persson et al., 2012; Joshi et al., 2015) in order to tune the coverage and power consumption of the wireless network, but is hidden from the user. In Joseph et al. (2013) duty cycles for Wireless Fidelity (WiFi) applications are used to determine personal exposure estimates. However, this data is not usable for cellular technologies. Additionally, published TX data contain no behavioral information of the user, which can have a large influence on the induced SAR (Krayni et al., 2016, 2017). A previously proposed technique (Wiart et al., 2000; Hillert, et al., 2006; Morrissey, 2007; Vrijheid et al., 2009; Kelsh et al., 2011; Kühn and Kuster, 2013a; Aerts et al., 2015) suggests the usage of application software on the smartphone or software modification on the smartphone in order to register TX powers during phone calls. However, the data provided in the aforementioned studies is either limited to a single subject (Wiart et al., 2000; Aerts et al., 2015), set-up with a phantom (Kühn and Kuster, 2013a), configurations with both a phantom and subject(s) (Kelsh et al., 2011), or volunteers with unknown behavioral patterns (Morrissey, 2007).

Although it is still unclear what the true exposure to RF radiation is during smartphone usage, most studies are convinced that the uplink exposure will be dominant (Lauer et al., 2013; Bolte et al., 2012; Roser, et al. 2013) in comparison to the downlink one. Therefore, current research efforts are focused on estimating this uplink exposure (Foerster et al., 2018) and finding potential ways to reduce uplink exposure. The techniques to reduce this exposure fall into two categories: technological and non-technological means of reducing exposure. The 
former methods focus on the introduction of a management of the exposure on a network level (Varsier et al., 2015) or on the level of the design of the phone, while the latter focus on behavioral aspects of the users with the current technology (FCC, 2017). An intuitive measure to reduce the SAR, at least in the subject's head, is to advice the usage of a headset or speaker mode while calling (FCC, 2017), since this increases the distance between one's head and the emitting phone. However, it is not clear that this might also have an impact on the power emitted by the phone. Numerical simulations have already demonstrated that the SAR induced by uplink depends heavily on the location and output power of a mobile phone (Gosselin et al., 2011), but are unsuitable to detect a potential correlation between location and output power, which might occur due to protocols in the network. Our goal is to measure whether the usage of a headset or speaker-modus actually reduces one's RF-EMF exposure to mobile phone uplink radiation.

Obviously, during phone calls a user is also exposed to sound emitted by the phone, and this exposure might have a negative impact on (perceived) hearing quality (Patel and Qureshi, 2013) and, similarly to RF-EMF exposure, depends on the usage scenario, i.e. using a headset or speaker mode can result in other exposure than using a smartphone at the ear. Additionally, both the sound pressure level at the ear and the usage scenario can influence speech intelligibility. This is a measure of how comprehensible speech is under certain hearing conditions, i.e. correct perception, identification, and repetition of speech signals, in this case isolated words. Smits and Houtgast (2004) demonstrated that speech intelligibility is lower for mobile phones in comparison to phones that use a fixed landline connection. However, no relationship with sound pressure level and usage scenario was shown for mobile phones. For three mobile phones evaluated by Jørgensen et al. (2015), transmission of speech through the mobile phones under study led to degraded speech intelligibility in comparison to the reference condition without transmission through mobile phones (Jørgensen et al., 2015).

The goals of this study are: first, to determine whether behavioral aspects can have an influence on the SAR induced by a smartphone; second, to quantify speech intelligibility and in-ear sound pressure level during those same exposure scenarios; and finally, come to a conclusion about which of the three studied scenarios results in the lowest co-exposure to RFEMF and in-ear sound pressure and whether changing from one usage scenario to another can serve as a non-technological way of reducing exposure to one or both of the studied physical agents. The novelties of this study are the following: we have measured, for the first time, the RF power emitted by a mobile phone during phone calls made by 53 subjects in a controlled environment in three exposure conditions: a call next to the ear, a call with headset (or earplugs), and a call using speaker-mode. These powers are then translated into SAR values. To our knowledge, this is the first study that reports SAR values and emitted powers obtained using actual phone calls made by several volunteers in controlled exposure conditions. In addition, it is also to the authors' best knowledge, the first paper studying the joint exposure to sound and RF-EMF.

\section{Materials and methods}




\subsection{Study design}

53 healthy subjects aged between 19 and 31 years ( 32 females and 21 males) were divided into two test groups of 29 ( 21 female and 8 male) and 24 (11 female and 13 male) subjects, respectively. The study was reviewed and approved by the ethical committee of Ghent University's Hospital. All subjects read and signed an informed consent form prior to the study. Subjects were recruited from the authors' colleagues and acquaintances, hence the relatively tight age span. We did not do a random population sampling in terms of age. This also ensured that all participants had normal hearing, and speech intelligibility would not have been influenced by (age-related) hearing loss. Additionally, the subjects' hearing was tested using tonal audiometry using the modified Hughson-Westlake technique. Air conduction thresholds were measured at octave band frequencies between $250 \mathrm{~Hz}$ and 8000 Hz. Participants were required to have a hearing threshold of $25 \mathrm{~dB}$ HL or better. Each group was assigned a different measurement site. The first measurement site was a one-room office (approx. $4 \times 4 \times 3 \mathrm{~m}^{3}$ ) in Ghent, Belgium, on the ground floor of a relatively old university building (Sint-Pietersnieuwstraat 41, 9000 Ghent, Belgium), while the second site was an office of slightly smaller dimensions $\left(3 \times 2 \times 3 \mathrm{~m}^{3}\right)$ on the 5 th floor of a modern (built in 2015) office building in Ghent (Technologiepark-Zwijnaarde 126, 9052 Ghent, Belgium). The first site featured single pane windows and brick walls, whereas the second building had double pane windows with reflective coatings as façade of a reinforced concrete structure. We expected an influence of the building structure on the indoor coverage by the (outdoor) wireless network. The coverage level influences the phone's emitted power levels. The experiments took place in the fall of 2015 and the spring of 2016.

The subjects were first asked to fill out a questionnaire related to their phone use. This questionnaire asked for personal characteristics such as: age, profession, preferred ear for phone calls, preferred hand for phone calls, whether the subject had previously used a mobile phone in one of the 3 studied conditions, and which of these conditions represented their average use. The dominant ear indicated in this questionnaire was used in further experiments with that subject. Full body length and body mass index were registered as well, but not further processed. After filling in the questionnaire, the subjects took place in a chair with the back of their heads against a headrest, which was adapted to their body height (Figure 1). The subjects were asked to keep their head in this pose during any call they made. Each subject was asked to make 18 phone calls with a duration of 5 minutes each (the used phone is discussed in the next section). They were asked to repeat the text they heard during each call. This ensured that data was recorded by the phone's microphone and that data was transmitted from the user to the network and consequently emitted RF power. Six of the calls were made while holding the phone next to their ear of preference, while using their hand of choice (no instructions were given). This exposure situation is referred to as 'At Ear'. A headset consisting of two earplugs connected using a wire to the same phone was used during six more calls (JIB Rasta, Skullcandy, Park City, Utah, USA). This situation is denoted 'Headset'. We did not use a wireless headset in order to avoid any RF-EMF exposure induced by the use of the headset. The remaining six calls were made using speaker mode, referred to as 'Speaker'. The phone was placed on a fixed position on the desk in front of the subject during the headset and speaker-mode calls, $50 \mathrm{~cm}$ from the back of the subject. The order in 
which the calls took place was randomized and was communicated to the subject before each call.

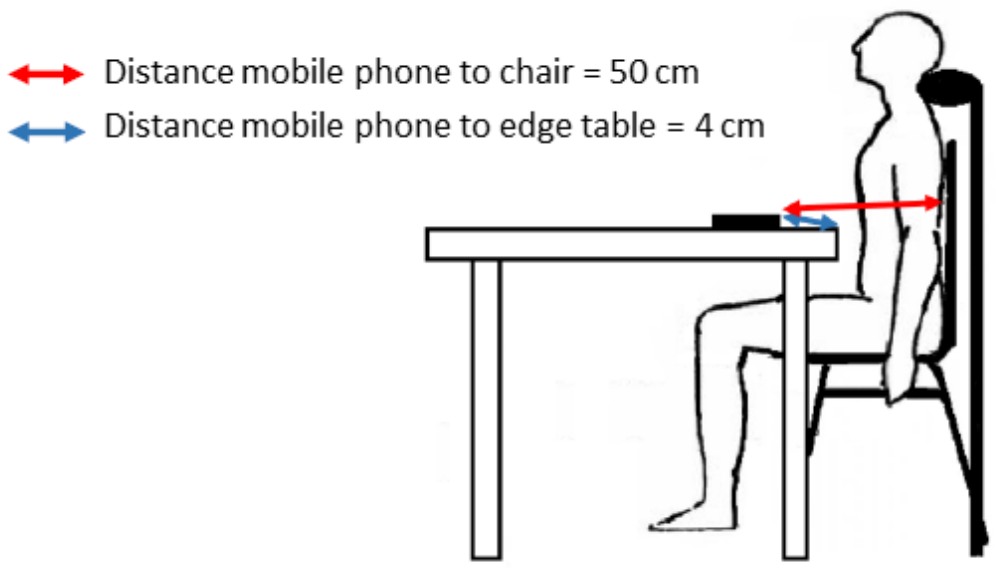

Figure 1. Illustration of the exposure set up.

\subsection{RF Measurements}

All calls were made using the same Nexus 5 (Google, Alphabet Inc. Mountain View, CA, USA). This phone was equipped with the Azenqos application (Freewill FX Company Limited, Bangkok, Thailand, http://www.azenqos.com/) (Aerts et al., 2015), which provides amongst other information the power transmitted by the phone (TX power) and received by the phone from the active base stations (RX power) during e.g. a telephone call or data traffic, with the phone using either the Global System for Mobile Communications (GSM) (i.e. the GSM $900 \mathrm{MHz}$ and GSM $1800 \mathrm{MHz}$ frequency bands) or 3rd generation (3G) Wideband Code Division Multiple Access (WCDMA) networks. This application ran a script through which the subject's phone made 18 calls (randomized order of content, same content for each subject) with $45 \mathrm{~s}$ intervals between each call. During these calls, the application registered the TX power (the power which was provided to the phone's antenna) in the $900 \mathrm{MHz}$ (879$915 \mathrm{MHz}), 1800 \mathrm{MHz}$ (1710-1785 MHz), and $1900 \mathrm{MHz}$ (1900-1980 MHz) uplink bands (Aerts et al., 2015). The frequency band was not fixed. The network provider chose which frequency band and technology $(2 \mathrm{G}, 3 \mathrm{G}$ or $4 \mathrm{G})$ was used, similar to real use-case scenarios. Other data provided by the application used in this study were the timestamps of each measurement, the used technology, and the activity log. The activity log indicated when a call was initiated and when it was terminated by providing a status of the phone. These were combined with the timestamps to determine the beginning and the end of each call. All timestamps in-between the beginning and the end of a call were saved, together with the corresponding TX powers. These were then used in the post-processing to assign each measured value to the correct subject and exposure situation. The TX power was stored in two different formats, depending on the used technology. First, in the GSM 900 (around 900 $\mathrm{MHz}$ ) and GSM 1800 (close to $1800 \mathrm{MHz}$ ) bands, the TX powers were stored as power level numbers (Kelsh et al., 2011). These can be converted to powers in decibel milliwatt (dBm). 
These powers are recorded with a resolution of $1 \mathrm{~dB}$ (Kelsh et al., 2011). Second, for WCDMA, the TX powers are directly logged in $\mathrm{dBm}$. The used phone could not use the LTE technology at the time of the experiment.

\subsection{Experimental Setup for Sound Measurements and Speech Intelligibility}

The experiments were performed in three types of background noise conditions: train noise, car noise, and no additional background noise ('quiet'). The train and car noise were recorded with a B-field microphone. From those recordings, fragments were selected to have minimal fluctuation in the presented background noise. For the experiments at test site 1, the sound fragment was converted to be compatible with the 5.1 surround system using Sound Forge pro 10.0 (Sony Corporation, Minato, Tokyo, Japan). For test site 2, a stereophonic setup was used and the same sound fragments were converted accordingly.

At test site 1, playback was done using five loudspeakers (Adam SX 1, Adam Audio, Berlin, Germany) and two subwoofers (Adam Sub8, Adam Audio, Berlin, Germany). The speakers were connected to a 24-channel sound card (Alpha-Link MADI AX, Solid State Logic, Inc., NY, New York, USA) connected to a desktop PC playing the sound fragments using Sound Forge Pro 10.0. For site 2, the space was smaller and therefore the setup had to be downsized, using two loudspeakers and one subwoofer, using the same equipment as in test site 1. For both sites, it was verified that the LAeq (the A-weighted equivalent continuous sound level in decibel measured over 10 minutes) level of the playback matched the original recordings, i.e. $70.0 \mathrm{~dB}(\mathrm{~A})$ for the car noise and $57.4 \mathrm{~dB}(\mathrm{~A})$ for the train noise.

Measurements of the sound pressure level (SPL) at the eardrum were done using an Aurical microphone, which is clinically used for measurement of hearing aid output at the eardrum. The Aurical microphone was calibrated in an anechoic room with a high-quality free-field microphone in accordance to previous work (Bockstael, 2009). As the measurements of the Aurical appeared unstable above $5000 \mathrm{~Hz}$, only the calibrated spectrum between $100 \mathrm{~Hz}$ and $5000 \mathrm{~Hz}$ was finally used to calculate the sound pressure level at the eardrum.

Prior to each listening condition (combination of background noise and position of the telephone: nine configurations in total), the participant was instructed to set the playback level of the telephone at a comfortable level, listening to a high quality recording of a documentary-style lecture.

For the actual speech intelligibility testing, recordings of the Dutch BLU word list (Wouters, 1994) - routinely used in speech audiometry - were played back to the mobile phone calling via Skype (Skype was used on the researchers end of the channel, not on the subjects' phone). Words were presented one word at a time, allowing the participant to repeat each word right after it was presented. Participants were asked to repeat each word as accurately as possible. Each list of the BLU consists of 10 words, and for each list the speech intelligibility score was the percentage of completely correctly identified words. The word list was randomized across all the exposure conditions.

After each test condition, participants were asked to rate on a scale from 1 to 5 how agreeable it was to listen to the speech in that condition (self-reported agreeability). At the very end of the experiment, participants were asked to complete a short questionnaire about their 
demographic data (age, gender, education), their dominant hand, and their use of smartphones (duration of usage, use of in-ears or speakers, preferred ear to use when calling).

\subsection{Numerical Simulations for SAR Determination}

The subjects were exposed to RF EMFs emitted by the smartphone. Part of RF EMFs are absorbed in the human body. This absorption is quantified using the SAR. This quantity is commonly averaged over a certain volume, mass, or tissue. In compliance studies, SAR is often averaged over the whole body or over $10 \mathrm{~g}$ cubes (ICNIRP, 1998). However, studies that focus on exposure to RF-EMFs from mobile phones commonly focus on exposure of the brain or brain regions (Schoeni et al., 2015; Guxens et al., 2016; Roser et al., 2016; Foerster, et al. 2018). Therefore, in this study, we have chosen to look at the brain-specific SAR $\left(\mathrm{SAR}_{\text {brain }}\right)$ (Thielens, et al. 2013). SAR cannot be measured in the body of the actual subjects, therefore, we have chosen to model the SAR using numerical simulations. To this aim, we have used the finite-difference time-domain (FDTD) technique in the software package Sim4Life (ZMT, Zürich, Switzerland). In this software, we have chosen to model the human body by the Duke phantom from the virtual family (Gosselin et al., 2015). This is a heterogeneous phantom consisting out of 81 tissues. The tissue properties were obtained from the Gabriel database (Gabriel, 1996). The exposure setup in the FDTD simulations is similar to the one described in Gosselin et al. (2014). The phone was modeled as a dipole antenna parallel to the phantom's main axis. Figure 2 shows the simulation setup.

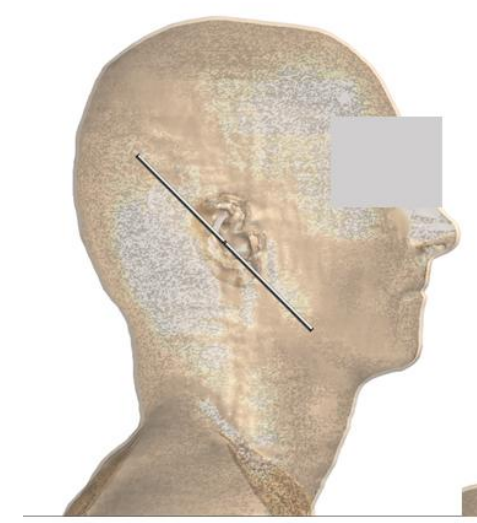

(a)

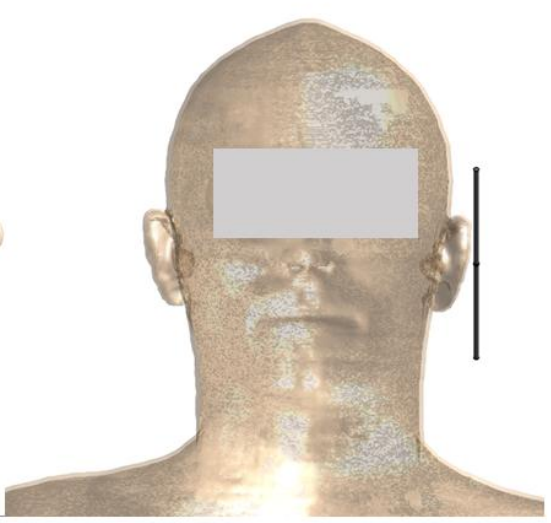

(b)

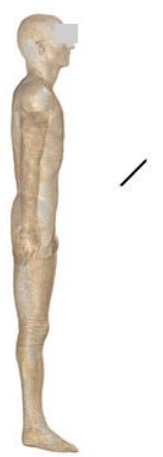

(c)

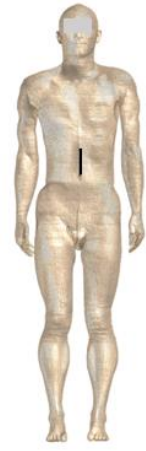

(d)

Figure 2. Simulation setup using the Duke phantom (Gosselin et al., 2014) in two configurations: (a) and (b) show the 'At Ear' configuration from a right and front view, respectively, while (c) and (d) show the simulations used to model the 'Speaker' and 'Headset' exposure conditions for a right and front view respectively. The shown dipole antenna (grey) resonates around $897 \mathrm{MHz}$.

Two different dipole antennas were used based on the designs presented in Aminzadeh et al. (2016): one that resonates (power reflection coefficient less than $-10 \mathrm{~dB}$ in free space) at 
$897 \mathrm{MHz}$ and a second one that resonates at $1800 \mathrm{MHz}$ both were fed with a $50 \mathrm{Ohm}$ input impedance. The dipole for $897 \mathrm{MHz}$ was modeled as two perfectly conducting cylinders of $7.5 \mathrm{~cm}$ with a $1.5 \mathrm{~mm}$ radius and a feeding gap of $1 \mathrm{~mm}$ in which a voltage source was placed. The dipole for $1800 \mathrm{MHz}$ was modeled as two perfectly conducting cylinders with length $36.35 \mathrm{~mm}$ and radius of $1.5 \mathrm{~mm}$, again with a feeding gap of $1 \mathrm{~mm}$ in which a voltage source was placed. The 'At Ear' exposure condition was modeled by placing the dipoles parallel to the phantom's main axis at $1 \mathrm{~mm}$ next to Duke's right ear. The dipoles were then rotated $45^{\circ}$ in a Sagittal plane with the upper cylinder rotating towards the back of the head, see Figure 2 (a). The other exposure conditions were modeled by placing the center of the dipoles in front of the phantom at $50 \mathrm{~cm}$ from the phantom's back at a height of $141 \mathrm{~cm}$ above the bottom of the phantom's feet. The dipole was centered w.r.t. the phantom's bounding box and was rotated $45^{\circ}$ in the mid-sagittal plane with the top cylinder rotating away from the phantom, see Figure 2 (c). The full simulation domain was discretized with grid steps of $0.5 \mathrm{~mm}$ for the dipole, $1.5 \mathrm{~mm}$ for the phantom, and adaptive grid steps in the surrounding region. The full phantom was included in the simulations in anatomical upright position. Krayni et al. (2017) demonstrated previously that phone efficiency and induced SAR values show little or no difference between upright and sitting phantom posture. The dipoles are fed a harmonic, sinusoidal wave of amplitude $1 \mathrm{~V}$ at $50 \mathrm{Ohms}$ at $897 \mathrm{MHz}$ and $1800 \mathrm{MHz}$, respectively. The simulations ran for 15 periods. After the simulation, the SAR values in the different tissues of the duke phantom were extracted. In order to determine $\mathrm{SAR}_{\text {brain, }}$ we averaged the SAR over the following tissues: Cerebrospinal fluid, Cerebellum, Hippocampus, Pons, Commissura Anterior, Pineal Body, Corpus Callosum, Commissura Posterior, Cerebrum white matter, Thalamus, Midbrain, Hypophysis, Hypothalamus, Medulla Oblongata, and Cerebrum Grey Matter (Gabriel, 1996; Gosselin et al., 2014; Thielens et al., 2013). These values were then renormalized to a TX power of $1 \mathrm{~W}$. We chose not to model the wire of the headset in the 'Headset' configuration.

\subsection{Data Processing and Analysis}

The registered TX powers during each call were pooled for all participants, calls and frequencies, but split for the three exposure conditions, the two locations, and the communication technology. We chose to split the data for the two locations, since the coverage and link with the network might have been different. We chose to split the data for the different telecommunication technologies since they have distinctly different ranges of operation in terms of emitted power. We did not split the GSM results in $900 \mathrm{MHz}$ and 1800 MHz. A Wilcoxon Rank Sum (WRS) test and a two-sided Kolmogorov-Smirnov (K-S) test were then used to determine whether the TX power in different exposure situations on the same test site were significantly different (significance level of 5\%). In a second step, all TX powers that were recorded for GSM were multiplied by the $\mathrm{SAR}_{\text {brain }}$ values at the appropriate frequency and exposure condition. Those instances where WCDMA was used to establish communication were not treated for SAR, because we did not have full information on the used frequency during those events. However, they were considered for the analysis of emitted powers. The obtained $\mathrm{SAR}_{\text {brain }}$ values were categorized in the same way and both a 
WRS test and two-sides K-S tests were used to determine any differences between the $\mathrm{SAR}_{\text {brain }}$ values under different test conditions.

To analyze the influence of background noise and cell phone position on the outcome variables, mixed model linear regression was applied using the LME4 package of the statistical software R (The R Project, The R Foundation for Statistical Computing, Vienna, Austria). Different models were built separately for the seven different outcome variables of interest: $S_{\text {brain }}$ value (1), sound exposure level measured by the free-field microphone (2) and in the ear (3), speech intelligibility scores (4), self-reports on how pleasant it was to listen to the speech (5), self-reported intelligibility of speech (6), and self-reported disturbance of the background noise during the experiment (7). For each of these models, the following steps were followed. By default in all the models, the participants were included as random factor, and the location at which testing took place (site 1 or site 2) was included as a fixed factor. Subsequently, for each of the models the influence of potential confounding variables (as obtained from the general questionnaire) was investigated: gender, age, dominant hand, occupation, preferred ear to hold a phone (left, right), preferred way of using the phone (at the ear, on speaker or with in-ears), and the average use of a phone. However, none of these variables appeared to be significant in any of the models $(p>0.05)$. Furthermore, the influence of the two main variables of interest was investigated: the background noise (no additional background noise ('Quiet' condition), car noise, train noise) and the position of the phone ('at ear', 'speaker', and 'headset'). In addition, the interaction effect between background noise and position were also investigated. To calculate the respective p-values of main and interaction effects, single term deletion was used: a chi-squared test was performed on the difference in AIC (Akaike Information Criterion) value of the model with and without the fixed variable under study. When of interest, pairwise Tukey post hoc comparisons were carried out.

Statistical model assumptions were verified by visual inspection of the residuals' Q-Q plot together with the Shapiro-Wilk test and the Kolmogorov-Smirnov test. For all models, assumptions were comfortably met; only for the speech intelligibility scores residuals seemed to deviate slightly from the assumptions, especially based on the Q-Q plot and distribution of the residuals. Transformation of the outcome variable did solve this issue partially, but as the different models for the original and the transformed variable did not lead to different conclusions, results for the original untransformed variable are reported here. It should be noted that for speech intelligibility score (percentage of correctly identified words, not selfreported speech intelligibility) the variation of the residuals clearly decreased with increasing score (scores close to $100 \%$ ). As this is especially an issue for quality of the predictions, and less for qualitative interpretation of the model, this model was maintained, nonetheless. Model-based parametric bootstrap was performed to visualize the model outcome, using the bootMer function from LME4. One thousand simulations were run for each model. In each simulation, new values of the random effects and the residual errors were generated.

\section{Results}




\subsection{TX Power Values}

Figure 3 shows the geometric averages of the powers emitted (TX power) during the registered calls. On test site 1, 287 calls used WCDMA and 235 used GSM. On site 2, the majority of the calls were executed using GSM, while only three calls (by two out of 24 subjects) used WCDMA. The WCDMA TX powers measured on test site 2 are shown in Figure 3 for completeness, but were not processed further due to a lack of data. There were no WCDMA calls on site 2 in the "At Ear" configuration. Overall, TX powers using GSM ranged from $16 \mathrm{dBm}$ to $33 \mathrm{dBm}$ on site 1 and from $11 \mathrm{dBm}$ to $33 \mathrm{dBm}$ on site 2, while TX powers using WCDMA ranged from $-13 \mathrm{dBm}$ to $9 \mathrm{dBm}$ (only site 1) (Figure 3). 


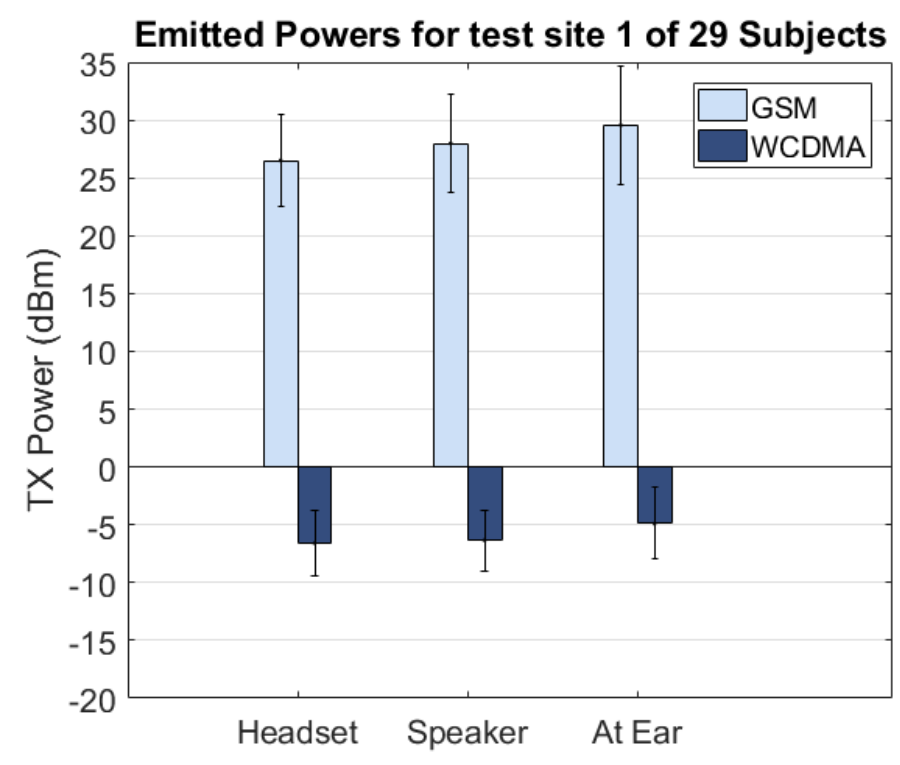

(a)

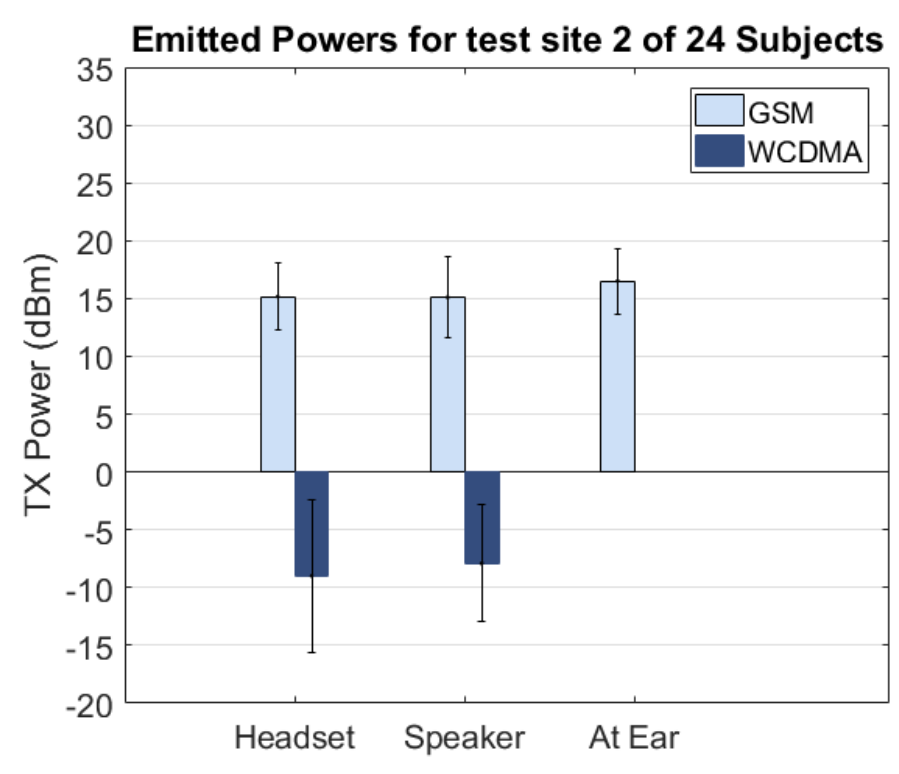

(b)

Figure 3: Emitted RF powers in three exposure conditions for (a) test site 1 and (b) test site 2. The bars indicate the geometric average TX powers, while the whiskers indicate the standard deviations on those averages.

The emitted powers using GSM in the 'At Ear' situation were significantly higher ( $\mathrm{p}<0.05$, KS and WRS test) than those in the other exposure conditions on both test sites. We attribute this to the additional loss (in the head and hands) that occurred when the subjects held the phone to the ear, which needed to be compensated for by increasing the emitted power in order to get the same received power at the base station. The same significant difference $(\mathrm{p}<$ $0.05, \mathrm{KS}$ and WRS test) was found for WCDMA on test site 1. Furthermore, a significant difference ( $\mathrm{p}<0.05$, KS and WRS test) in TX powers was found between the two 
measurement sites for GSM in each exposure situation, which justifies the separation in two different pools of data. Finally, the TX power during GSM technology usage was always found to be significantly higher ( $\mathrm{p}<0.05, \mathrm{KS}$ and WRS test) than WCDMA.

\section{2. $\quad S A R_{\text {brain }}$ Values}

Table 1 lists the $\mathrm{SAR}_{\text {brain }}$ values (normalized to an antenna input power of $1 \mathrm{~W}$ ) found in the two simulated exposure scenarios and for the two simulated frequencies. $S A R_{\text {brain }}$ is 100 to 350 times higher in the 'At Ear' scenario, due to the shorter distance to the brain.

Table 1. Simulation results of SAR $R_{\text {brain }}$ for an input power of $1 \mathrm{~W}$ into one of the dipoles used to model the mobile phone. The configuration of the simulations is shown in Figure 2.

\begin{tabular}{r|cc}
\hline & \multicolumn{2}{|c}{$\mathbf{S A R}_{\text {brain }}(\mathbf{W} / \mathbf{k g})$} \\
\hline & $\mathbf{8 9 7} \mathbf{~ M H z}$ & $\mathbf{1 8 0 0} \mathbf{M H z}$ \\
Headset Ear & 0.132 & 0.233 \\
& $1.4 \times 10-3$ & $6.65 \times 10-4$ \\
\hline
\end{tabular}

The normalized SAR brain values were then multiplied by the experimental GSM TX powers (Figure 3) in order to obtain the actual $S_{A R}$ brain values in the three studied exposure conditions for the two measurements sites (Figure 4). In Figure 4, the actual SAR brain values are presented on a logarithmic scale.

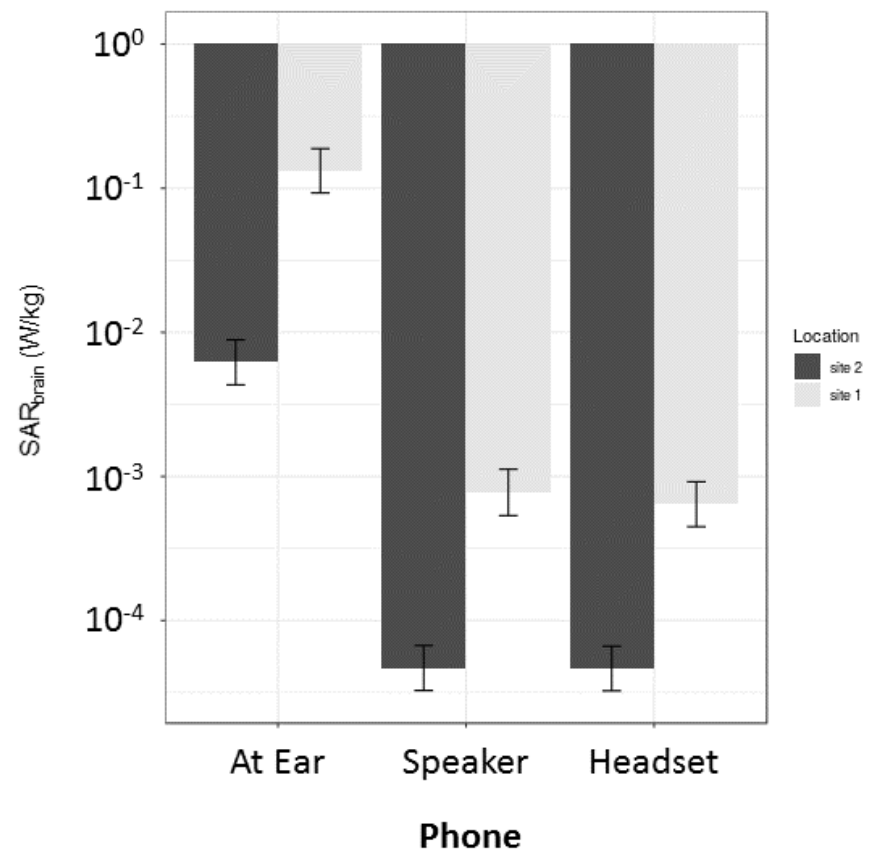

Figure 4: Predicted mean SAR brain values for GSM calls (900 and $1800 \mathrm{MHz}$ ) in three exposure conditions on two test sites (29 subjects on site 1 and 24 subjects on site 2).The error bars depict the $95 \%$ confidence intervals.

The position of the phone (at the ear, with headset, on speaker) had a highly significant influence on $\mathrm{SAR}_{\text {brain }}$ levels ( $\mathrm{p}<0.0001$ ), as did the location (site 2 and site 1 ) where the experiment has been carried out $(p<0.0001)$. The influence of phone position was expected as both the simulated SAR in the 'At Ear' exposure condition and the TX power were higher 
than in the other conditions. Also, the influence of the location was expected after analysis of the TX power, since the levels of TX were found to be different on both locations. Both variables position and location remained highly significant in an additive model containing the two variables (both p-values well below 0.001). Moreover, even the interaction effect between position and location appeared significant ( $p<0.0001)$. Comparing the magnitude of the estimates of the model's fixed effects showed that estimates of the main effects were considerably larger than those of the interaction effects. This suggest that the significant interaction was merely a slight "correction" from the more pronounced effects of phone position and experiment's location on SARbrain values: SARbrain values for 'speaker mode' and 'headset' were slightly closer together for both locations compared to the difference in SARbrain values between locations for the phone held at the ear. Finally, as expected the background noise had no significant influence on SAR levels $(p>0.1)$ and this variable was not included in the final statistical model.

\subsection{Sound Pressure Level}

Figure 5 shows the measured Aurical SPL on a logarithmic scale (in $\mathrm{dB}$ ) in the three RF exposure conditions and for three conditions of background noise. For the SPL measured by the Aurical microphone, the baseline model included the variable participant (random) and location (fixed). It should be noted that location had no significant effect in this model ( $\mathrm{p}>$ 0.1), but was kept nonetheless because of the known difference in background noise setup between the two locations. Introducing the variables background noise and phone position into the baseline models showed a strong interaction effect of these variable on the SPL measured by the Aurical microphone ( $p<0.00001)$.

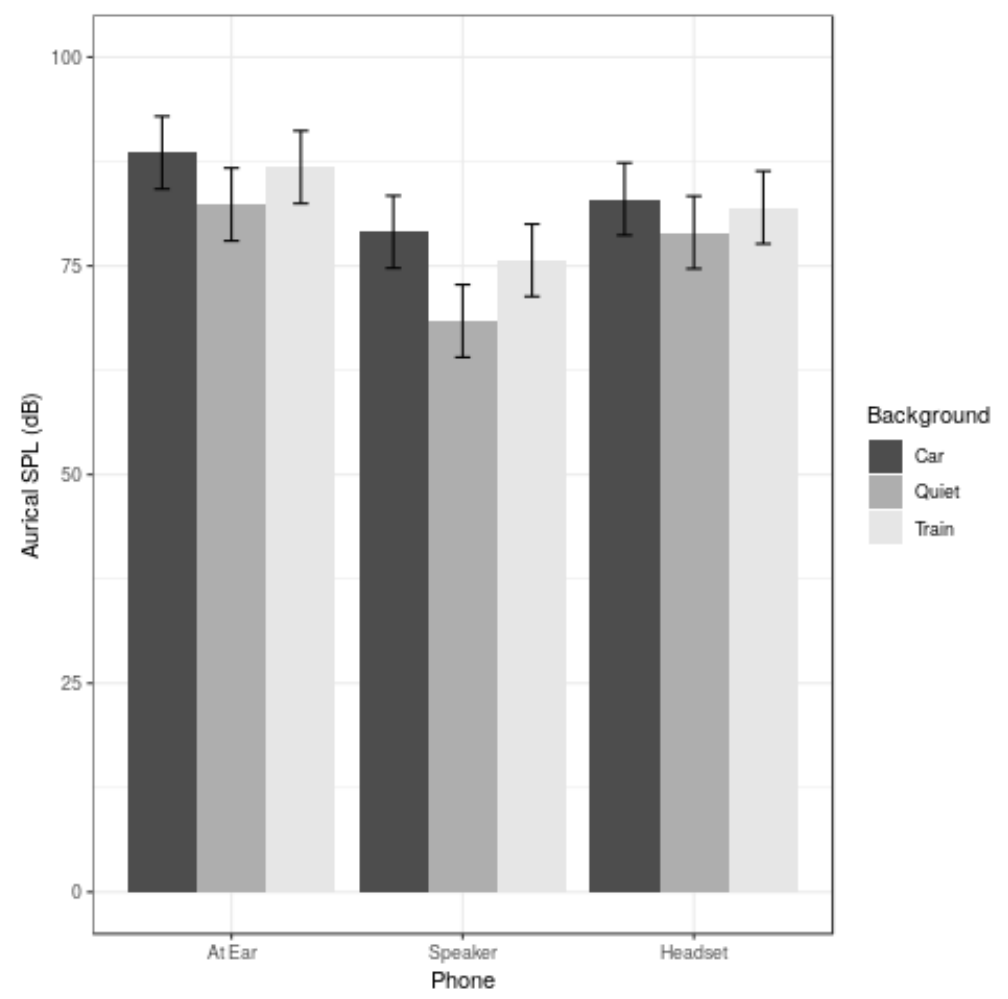

Figure 5: Mean sound pressure measured by the Aurical microphone as a function of background condition and position of the phone. Error bars span the $95 \%$ confidence interval. 
Post-hoc testing showed that within a specific noise condition (quiet: no additional background, car, or train noise) SPLs were significantly higher when the phone was held at the ear compared to headset and speaker-mode ( $\mathrm{p}<0.001$ for all relevant comparisons) and that SPLs with headset were significant higher than levels in speaker-mode ( $p<0.001$ for all relevant comparisons).

When the phone was put in speaker-mode, we observed the clearest significant differences in SPLs in terms of variable noise conditions: levels when car noise was present were significantly higher than SPL levels with in train noise or without additional noise, and SPL levels in case of train noise were significantly higher than in the case without additional noise ( $p<0.001$ for all relevant comparisons).

In the other two phone positions, levels for the different noise conditions were somewhat closer together (Figure 5). At the ear, the SPL levels with noise (car and train) present noise conditions clearly exceeded the levels without additional background noise ( $p<0.001$ for all relevant comparisons), but no significant difference was found between the levels in case of car noise and in case of train noise $(\mathrm{p}>0.1)$. For the headset case, similar results were found (car noise vs quiet $\mathrm{p}<0.001$; train noise vs quiet $\mathrm{p}<0.01$; car noise vs train noise $\mathrm{p}>0.1$ ).

\section{4. $\quad$ Speech Intelligibility}

Figure 6 depicts the speech intelligibility as a function of background noise conditions (car noise, no added background noise, train noise) and the position of the cell phone. The experiment's location had no significant influence on speech intelligibility scores ( $p>0.1)$. The position of the phone (at the ear, headset, on speaker) had a highly significant influence on speech intelligibility ( $p<0.0001$ ), as did the background noise condition $(p<0.0001)$. The interaction effect between position and location also appeared significant $(p<0.0001)$.

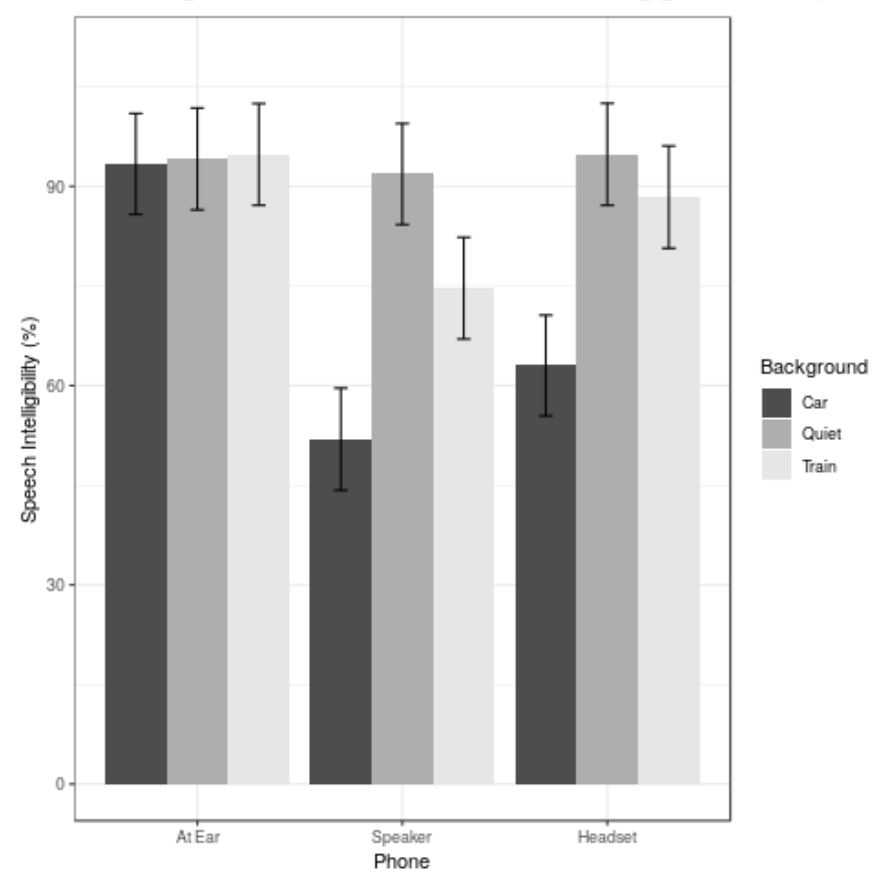

Figure 6: Mean speech intelligibility score (\%) as a function of position of the cell phone and background noise conditions. Error bars span the $95 \%$ confidence interval. 
Tukey post-hoc testing confirmed that the 'At Ear' position resulted in the best listening conditions, cancelling out the difference between the different background noise conditions ( $p>0.1$ for all relevant post-hoc comparisons).

In quiet conditions without additional background noise, the position of the phone had no significant effect on the speech recognition scores $(\mathrm{p}>0.1$ for all relevant post-hoc comparisons). For car background noise, the effect of the position of the phone appeared to be the most critical. When the phone was used on speaker, the speech recognition scores were the lowest, lower than at the ear $(\mathrm{p}<0.001)$ and with a headset $(\mathrm{p}<0.001)$. With a headset, speech recognition was still markedly lower compared to the 'at-ear' configuration ( $p<$ 0.001). Finally, in the train noise case, the in-speaker mode delivered speech intelligibility results that were clearly worse compared to the ones for the 'at ear' and 'headset' ( $p<0.001$ for all relevant comparisons) positions, but still significantly better than the ones for the car noise case $(\mathrm{p}<0.001)$. Moreover, no significant difference between 'headset' and the optimal 'at ear' conditions could be found ( $p>0.1$ for all relevant comparisons).

\subsection{Self-Reported Agreeability}

For the agreeability of listening to the speech (Figure 7), the baseline model included the variable participant (random) and location (fixed). As with the SPL model, location had no significant effect in this model ( $p>0.1$ ), but was kept nonetheless because of the known difference in background noise exposure between the two locations. Introducing the variables 'background noise' and 'phone position' into the baseline models showed a strong interaction effect of these variable on the reported agreeability $(p<0.00001)$.

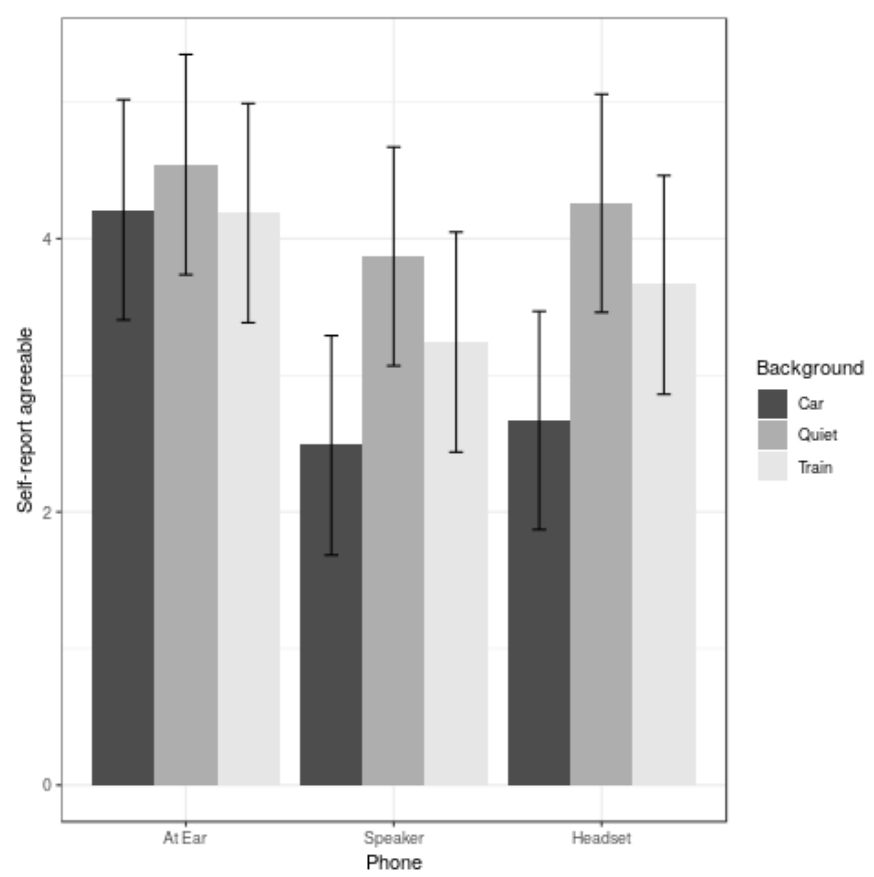

Figure 7: Mean rating of agreeability of listening to speech as a function of position of the cell phone and background noise condition. The error bars depict the $95 \%$ confidence interval.

The position of the phone clearly had the strongest effect in the car noise case: the 'At Ear' position clearly had higher ratings compared to 'Speaker' $(p<0.001)$ and 'Headset' $(p<$ 
0.001). However, no significant difference was found $(\mathrm{p}>0.1)$ between 'Speaker' and 'Headset'.

For the train noise case, the position of the phone had similar significant effects, albeit less pronounced. The largest difference was found between ratings 'At Ear' versus 'Speaker' $(\mathrm{p}<$ 0.001). In addition, ratings for 'At Ear' were also better than those for 'Headset' $(0.05>p>$ 0.01). Finally, no clear difference was found between ratings of 'Headset' versus 'Speaker' $(0.1>\mathrm{p}>0.05)$.

Without additional background noise, the only systematic difference in rating of agreeability of speech was found between 'At Ear' and 'Speaker' $(p<0.001)$. For the other comparisons, no significant differences were found ( $p>0.1$ for all relevant comparisons).

When the phone was held in the 'At Ear' configuration, no significant differences were found between ratings in the different background conditions (car, train, no additional background noise; $\mathrm{p}>0.1$ for all relevant comparisons).

Finally, when a headset was used or when the phone was used on speaker, rating were clearly less positive for car noise compared to quiet ( $\mathrm{p}<0.01$ for all relevant comparisons) as well as compared to train noise ( $\mathrm{p}<0.01$ for all relevant comparisons). Train noise was also rated less positive than the quiet condition ( $\mathrm{p}<0.01$ for all relevant comparisons).

\section{Discussion}

\subsection{TX Power Values and Analysis}

TX powers were recorded for 53 subjects at two different building sites in three different exposure conditions. We found higher TX powers when the smartphone was held next to the head in comparison to using a headset or calling in speaker mode. These results can be used as additional input for governmental institutions that issue guidelines on smart phone usage with the aim of lowering exposure.

WCDMA TX powers have previously been reported in Persson et al. (2012), where median WCDMA output powers during voice calls of $-17 \mathrm{dBm}$ to $-14 \mathrm{dBm}$ were reported for a Swedish network of a relatively large group of users. Their data set was obtained for unregistered exposure conditions (modus of operating the phone), and at different locations in Sweden for more than 100k hours of call time. The interquartile range (50\% of all registered TX powers fall into this range) on the TX powers during voice calls in Persson et al. (2012) was more than $30 \mathrm{~dB}$ around the median, while the full range of measured powers was more than $55 \mathrm{~dB}$. Our measured WCDMA data $(-13 \mathrm{dBm}$ to $9 \mathrm{dBm})$, for variable subjects, one location, and three exposure conditions, fall in the highest quartile of their measured data. Note that our measurements were executed in an indoor environment, where TX powers towards the outdoor network are expected to be higher than outdoors. In Joshi et al. (2015), mean and median values of $5 \mathrm{dBm}$ and $-11.5 \mathrm{dBm}$, respectively, were reported for WCDMA voice calls in India. Our measurement data $(-13 \mathrm{dBm}$ to $9 \mathrm{dBm}$ for WCDMA) are in the three upper quartiles of the distribution for voice calls presented in Joshi et al. (2015). Lonn et al. (2004) reported TX power using GSM voice calls in Sweden in four defined areas (rural, small urban, suburban, and city). They found median TX powers between $18 \mathrm{dBm}$ and 21 $\mathrm{dBm}$ in 'suburban' and 'city' areas during weekdays, which is in between the median values 
we observed for test site $1(23 \mathrm{dBm}$ to $32 \mathrm{dBm})$ and site 2 (13 dBm to $17 \mathrm{dBm})$. Kühn and Kuster (2013a) did not report absolute values for GSM and WCDMA calls in Switzerland, but found similar differences between GSM and WCDMA as in this study (Figure 3). In Aerts et al. (2015), the same application was used to record the emitted powers during GSM voice calls for a single subject in a moving train to the fixed network outside the train. A median emitted power of $18 \neg 21 \mathrm{dBm}$ was reported for GSM on the train. The median values measured in this study ranged from $23 \mathrm{dBm}$ to $32 \mathrm{dBm}$ on site 1 and from $13 \mathrm{dBm}$ to $17 \mathrm{dBm}$ on site 2, depending on the subject and exposure situation.

Kelsh et al. (2011) also found large differences between the average emitted powers during GSM and CDMA phone calls: $10-20 \mathrm{~dB}$ in Rural, Suburban, and Urban scenarios. These differences are smaller than what we observed. Kelsh et al. (2011) also show that the average differences between GSM and CDMA are larger in stationary conditions than in moving scenarios, which could partly explain why we find larger differences in our stationary measurements than what was found by Kelsh et al. (2011).

The calls made in this study are relatively short. Therefore, the elevated higher powers during initialization of a GSM call (Aerts et al., 2015) could have more relative weight in the determination of the geometrically averaged TX power in comparison to longer calls.

In general, the comparison with literature above shows that our measured TX powers are realistic for the used technologies, configurations, and locations. The aforementioned references do show that there is a relatively large spread (> factor 1000) in TX power values that can be found in literature.

\section{2. $\quad S A R_{\text {brain }}$ Values and Analysis}

Since the measured TX powers were significantly higher for the 'At Ear' exposure situation

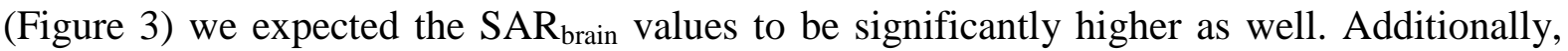
higher SAR values in the head were found for antennas near the ear in comparison to the other two exposure scenarios (approximately a factor 100 higher, Table 1). Obviously, these results are not valid for other SAR metrics. For example, the whole-body averaged SAR could be higher in the 'Speaker' or 'Headset' scenario - this depends heavily on the antenna in the mobile phone and its directivity towards the body in all exposure situations as well as the dielectric properties (conductivity) of the head tissues which are dependent on parameters like subject's age and gender.

Table 1 lists the $\mathrm{SAR}_{\text {brain }}$ values obtained from FDTD simulations. We found higher $\mathrm{SAR}_{\text {brain }}$ values in the 'At Ear' exposure conditions than in the other exposure condition for both studied frequencies: a factor 94 higher at $897 \mathrm{MHz}$ and a factor 350 at $1800 \mathrm{MHz}$, for the same input power. This was expected since higher electric fields in the brain were expected for a dipole closer to the head. Additionally, we found a higher $\mathrm{SAR}_{\text {brain }}$ at $1800 \mathrm{MHz}$ in comparison to $897 \mathrm{MHz}$ for the 'at ear' position. This is in line with Gosselin et al. (2011) where a higher head-averaged SAR was found for dipoles resonating at $1800 \mathrm{MHz}$ in comparison to dipoles resonating at $900 \mathrm{MHz}$ in five different phantoms in different 'At Ear' configurations. It should be noted that in the same study (Gosselin et al., 2011) numerical simulations were executed for four real phones. For those simulations with realistic phone models, the $\mathrm{SAR}_{\text {brain }}$ at $900 \mathrm{MHz}$ was found to be either higher than or comparable to the 
$\mathrm{SAR}_{\text {brain }}$ at $1800 \mathrm{MHz}$. Adibzadeh et al. (2015) found higher $\mathrm{SAR}_{\text {brain }}$ at $843 \mathrm{MHz}$ versus

Krayni et al. (2017) found higher whole-body averaged SARs normalized to an output power of $1 \mathrm{~W}$ for a mobile phone emitting at $900 \mathrm{MHz}$ at the ear in comparison to a tablet emitting at $1.9 \mathrm{GHz}$ in front of the body. We find similar differences between $\mathrm{SAR}_{\text {brain }}$ obtained for the 'at ear' configuration at $897 \mathrm{MHz}$ and $\mathrm{SAR}_{\text {brain }}$ in the other two configurations at $1800 \mathrm{MHz}$. Krayni et al. (2017) found no difference in whole-body average SAR and radiation efficiency of the phone in sitting and standing positions. This justifies our choice to numerically model the phantom in upright position.

Our results, displayed in Figure 4, showed that $\mathrm{SAR}_{\text {brain }}$ can be reduced when a phone is used with a headset or in speaker mode. These results are important for other studies that investigate effects of RF exposure on brain functionality.

\subsection{Speech Intelligibility and Sound Exposure}

Holding the cell phone at the ear appears to be the most favourable position for speech perception (Figures 6 and 7). In this position, the highest speech intelligibility scores in background noise (train/car) were obtained. Moreover, the influence of noise appeared to be altogether negligible, as no difference could be found between scores in background noise and in quiet. These findings were further confirmed by self-report on how agreeable it is to listen to the speech. Figure 6 suggest that there might have been ceiling effects in the speech intelligibility measurements. Participants with normal hearing will perform close to optimal in some conditions, which might lead to similar results in those conditions. 
Yet, the 'at ear' position is the situation with the highest sound pressure levels measured at the eardrum (Figure 5). It should be noted that the recorded level is the overall level (speech plus noise if present) and that the participants were asked before each test condition to adjust the speech level to a comfortable listening level. On average, $82.4 \mathrm{~dB}$ was measured at the ear in the quiet condition, $86.9 \mathrm{~dB}$ with train noise, and $88.5 \mathrm{~dB}$ with car noise. As these are levels at the eardrum, which would have to undergo head-related transfer functions in order to scale them to free-space levels, these values are not directly comparable to directives for safe sound exposure levels which are all set for free/diffuse field exposure (Hammershøi and Møller 2008). However, for speech, the difference between in-ear and free-field levels can be estimated to be around $6 \mathrm{~dB}$ based on previous work with a similar measurement setup (Bockstael et al. 2011). Based on this conversion, exposure levels fully complied with the 85 $\mathrm{dB}(\mathrm{A})$ level deemed to be safe for 8-hours exposure according to the European Directive for occupational noise exposure ("Directive 2003-10-EC on the Minimum Health and Safety Requirements Regarding the Exposure of Workers to the Risks Arising from Physical Agents (Noise)" 2003). Nonetheless, even with free-field conversion, the measured levels did not fall below the critical levels of $74 \mathrm{~dB}$ (for $4000 \mathrm{~Hz}$ ) and $78 \mathrm{~dB}$ (A) (for broadband noise) at which temporary threshold shifts are found for 8-hour exposure (Mills, Adkins, and Gilbert 1981). Therefore, based on this work, a risk from auditory effects from long-lasting exposure to cell phone conversation in background noise cannot be ruled out. However, it is unlikely for 8hour-long calls to be made. To date, mixed findings have been reported on a potential risk of hearing loss due to noise sound exposure from making phone calls; some studies reported no effect (Sagiv et al. 2018), whereas others found changes linked to cell phone use for specific audiological parameters (Panda et al. 2011).

\subsection{Simultaneous Exposure to RF-EMF and Sound Pressure}

Both in terms of RF exposure (Figure 4) and sound pressure exposure (Figure 5) using the cell phone on speaker appears advantageous, with SPLs well below potentially unsafe levels (quiet: on average $68.4 \mathrm{~dB}$; train noise: $75.6 \mathrm{~dB}$; car noise: $79.1 \mathrm{~dB}$ ), especially when taking in account a factor of $6 \mathrm{~dB}$ between eardrum and free field levels. In addition, using the phone hands-free was found to be advantageous for general driving conditions as it reduces motor interference from manipulating and holding the phone, thus giving drivers a better control over their vehicle (Collet, Guillot, and Petit 2010).

Despite these advantages of using the cell phone on speaker, this condition has a clear negative effect on speech perception in background noise, see Figure 6. In quiet conditions, no significant decrease in speech intelligibility was seen, but the speech recognition scores dropped significantly in car noise and to a lesser extent also in train noise (Figure 6). The different effects of car noise and train noise found in this study can most probably be attributed to a difference in signal-to-noise ratio, as the car noise was clearly more elevated than the train noise (respectively $57.4 \mathrm{~dB}(\mathrm{~A})$ and $70.0 \mathrm{~dB}(\mathrm{~A})$ for Leq over 10 minutes). Speech recognition scores decline strongly for decreasing signal-to-noise ratio once a critical noise level is surpassed (Neuman et al. 2010). 
Finally, the listening condition with a headset takes an intermediate position. The SPLs are higher than 'speaker', but clearly lower than 'at ear'. Because the headset allowed to play the speech signal in both ears - and not only on one side as during the 'at ear' position participants might have perceived a more advantageous signal-to-noise ratio because of the binaural listening advantage (Robinson and Dadson 1957), and therefore, might have lowered the playback level of the speech signals in this condition.

Despite this theoretical listening advantage, speech intelligibility is markedly lower than when the phone is held at the ear, especially in car noise, albeit still better than in speaker mode. At this point, technical failure in the phone-headset combination cannot be ruled out. For instance, it is possible that the noise was picked up by the cell phone microphone (not shielded) and somehow played back together with the speech, especially degrading the speech signal in the condition with the highest noise level (car). Another possible explanation is that participants increased the level of the speech in the 'at ear' condition, also based on the noise level they heard in the contralateral ear. This would de facto result in a more advantageous signal-to-noise ratio at the side where the phone was held, because that ear is much more shielded from the background noise than the contralateral ear. In addition, it is known that a clear separation between signal and noise (one ear predominantly exposed to the noise, the other predominantly exposed to speech) improves speech intelligibility (Bockstael et al. 2011). Especially in highest levels of background noise (car), shielding and spatial separation would have the most distinct effect and improve speech intelligibility scores. Further research with other types of headsets is needed here.

\section{Conclusions}

In this study, the transmitted radio-frequency electromagnetic field (RF-EMF) power was recorded for 53 subjects who carried out phone calls in three controlled exposure scenarios: calling with the phone at the ear, calling in speaker-mode, and calling with a headset. Phone calls were carried out using the Wideband Code Division Multiple Access (WCDMA) and Global System for Mobile communication (GSM) technologies. For both communication technologies, the emitted power of the phone at the ear was higher than the emitted power in the two other exposure conditions. Moreover, Finite-Difference Time-Domain simulations for a fixed emitted power showed that the brain-averaged specific absorption rate $\left(\mathrm{SAR}_{\text {brain }}\right)$ was higher when the emitting antenna was located close to the ear than in speaker-mode and headset (94 to 350 times higher). The $\mathrm{SAR}_{\text {brain }}$ values were then rescaled using the measured powers emitted using GSM technology during the experiments in order to estimate the RFEMF absorption in the three studied scenarios. It was concluded that the $\mathrm{SAR}_{\text {brain }}$ will be reduced by more than a factor 100 when either speaker-mode or a headset are used, in comparison to calling next to the ear. These results can be used as additional input for governmental institutions that issue guidelines on smart phone usage with the aim of lowering exposure. Furthermore, in conditions where background noise was present, speech perception was found to be the best when the phone was held at the ear in comparison to using the phone in speaker mode or with a headset. However, the exposure to sound pressure was also found to be the highest in the at-ear configuration, while it was lowest with the phone in speaker mode. Overall, the speaker-mode condition was found to be the 
configuration in which both exposures to RF-EMFs (in terms of $\mathrm{SAR}_{\text {brain }}$ ) and sound pressure were lowest, although reducing exposure by changing to this configuration does come at a cost in terms of speech intelligibility, in particular in noisy environments. Using a wired headset, on the other hand, was found to significantly reduce $S_{A} R_{\text {brain }}$ while only reducing speech intelligibility by a small, yet significant in noisy conditions, amount in comparison to using the phone at the ear. These results are important for smartphone users that might be concerned about both exposure during their calls and about the quality of their calls.

\section{Acknowledgements}

This project has received funding from the European Union's Horizon 2020 research and innovation programme under the Marie Skłodowska-Curie grant agreement No 665501 with the research Foundation Flanders (FWO). AT is an FWO [PEGASUS] ${ }^{2}$ Marie Skłodowska-Curie Fellow. S. A. is a postdoctoral fellow of the FWO. 


\section{REFERENCES}

Adibzadeh F, Bakker JF, Paulides MM, Verhaart RF, van Rhoon GC. Impact of Head Morphology on Local Brain Specific Absorption Rate From Exposure to Mobile Phone Radiation. Bioelectromagnetics 36: 66-76, 2015.

Aerts S, Plets D, Thielens A, Martens L, Joseph W. Impact of a Small Cell on the RF-EMF Exposure in a Train. Int. J. Environ. Res. Public Health 12: 2639-2652, 2015.

Aminzadeh R, et al. "On-Body Calibration and Measurements Using Personal Radiofrequency Exposimeters in Indoor Diffuse and Specular Environments: Calibration of Personal Exposimeters.” Bioelectromagnetics 37 (5): 298-309, 2016.

Bockstael A, et al. "Verifying the attenuation of earplugs in situ: method validation on human subjects including individualized numerical simulations." The Journal of the Acoustical Society of America 125.3: 1479-1489, 2009.

Bockstael A, De Coensel D, Botteldooren D, D’Haenens W, Keppler H, Maes L, Philips B, Swinnen F, Vinck B. "Speech Recognition in Noise with Active and Passive Hearing Protectors: A Comparative Study." The Journal of the Acoustical Society of America 129 (6). Acoustical Society of America: 3702-15. WOS:000291727000041, 2011.

Bolte JF and Eikelboom T. Personal radiofrequency electromagnetic field measurements in The Netherlands: exposure level and variability for everyday activities, times of day and types of area. Environ Int. 48:133-42, 2012.

Christ A, Gosselin MC, Christopoulou M, Kühn S, Kuster N. Age-dependent tissue-specific exposure of cell phone users. Physics in Medicine and Biology 55: 1767-1783, 2010.

Collet C, Guillot A, Petit C. "Phoning While Driving Ii: A Review of Driving Conditions Influence." Ergonomics 53 (5). Taylor \& Francis: 602-16, 2010.

"Directive 2003-10-EC on the Minimum Health and Safety Requirements Regarding the Exposure of Workers to the Risks Arising from Physical Agents (Noise)." 2003. In. Brussels: European Parliament; Council.

Federal Communications Commission (FCC). Wireless Devices and Health Concerns. Last accessed on 24th Feb 2017 at https://www.fcc.gov/consumers/guides/wirelessdevices-and-health-concerns.

Foerster M, Thielens A, Joseph W, Eeftens M, Röösli M. A Prospective Cohort Study of Adolescents' Memory Performance and Individual Brain Dose of Microwave Radiation from Wireless Communication. Environ Health Perspectives 126(7): 13 pages, July 2018.

Gati A, Conil E, Wong M-F, Wiart J. Duality Between Uplink Local and Downlink WholeBody Exposures in Operating Networks. IEEE Trans. Electromagn. Compat. 52:829836, 2010.

Ghanmi A, Varsier N, Hadjem A, Conil E, Picon O, Wiart J. Analysis of the Influence of Handset Phone Position on RFE xposure of Brain Tissue. Bioelectromagnetics 35: 568-579, 2014.

Gosselin MC, Kühn S, Crespo-Valero P, Cherubini E, Zefferer M, Christ A, Kuster N. Estimation of Head Tissue-Specific Exposure From Mobile Phones Based on Measurements in the Homogeneous SAM Head. Bioelectromagnetics 32:493-505, 2011.

Gosselin MC, Neufeld E, Moser H, Huber E, Farcito S, Gerber L, Jedensjö M, Hilber I, Di Gennaro F, Lloyd B, Cherubini E, Szczerba D, Kainz W, Kuster N. Development of a new generation of high-resolution anatomical models for medical device evaluation: the Virtual Population 3.0. Phys Med Biol. 59(18):5287-5303, 2014. 
Guxens, M., Vermeulen, R., van Eijsden, M., Beekhuizen, J., Vrijkotte, T.G.M., van Strien, R.T., Kromhout, H., and Huss, A. (2016). Outdoor and indoor sources of residential radiofrequency electromagnetic fields, personal cell phone and cordless phone use, and cognitive function in 5-6 years old children. Environ. Res. 150, 364-374.

Hammershøi D, and Møller H. "Determination of Noise Immission from Sound Sources Close to the Ears." Acta Acustica United with Acustica 94 (1). S. Hirzel Verlag: 114 29, 2008.

Hillert L, Ahlbom A, Neasham D, Feychting M, Järup L, Navin R, Elliott P. Call-related factors influencing output power from mobile phones. J. Expo. Sci. Environ. Epidemiol. 16:507-14; 2006.

International Commission on Non-Ionizing Radiation Protection (ICNIRP). Guidelines for limiting exposure to time-varying electric, magnetic, and electromagnetic fields (up to 300 GHz). Health Phys.74(4):494-522, 1998.

International Electrotechnical Commission (IEC), Methods for the assessment of electric, magnetic and electromagnetic fields associated with human exposure: Procedure to measure the Specific Absorption Rate (SAR) for hand-held mobile wireless devices in the frequency range of $300 \mathrm{MHz}$ to $3 \mathrm{GHz}$, standard IEC62209/CD, 1st July 2001.

Jørgensen, Søren, Jens Cubick, and Torsten Dau. "Speech intelligibility evaluation for mobile phones." Acta Acustica United with Acustica 101.5 (2015): 1016-1025.

Joseph W, Pareit D, Vermeeren G, Naudts D, Verloock L, Martens L, Moerman I.

Determination of the duty cycle of WLAN for realistic radio frequency electromagentic field exposure assessment. Prog Biophys Mol. Biol. 111(1): 30-36, 2013.

Joshi P, Agrawal M, Thors B, Colombi D, Kumar A, Törnevik C. Power Level Distributions of Radio Base Station Equipment and User Devices in a 3G Mobile Communication Network in India and the Impact on Assessments of Realistic RF EMF Exposure. IEEE Access 3: 1051-1059, 2015.

Kelsh MA, Shum M, Sheppard AR, McNeely M, Kuster N, Lau E, Weilding R, Fordyce T, Kühn S, Sulser C. Measured radiofrequency exposure during various mobile-phone use scenarios. Journal of Exposure Science and Environmental Epidemiology 21: 343-354, 2011.

Krayni A, Hadjem A, Sibille A, Roblin C, Wiart J. A Novel Methodology to Evaluate Uplink Exposure by Personal Devices in Wireless Networks. IEEE Trans on EMC. 58(3): 896-906, 2016.

Krayni A, Hadjem A, Vermeeren G, Sibille A, Roblin C, Joseph W, Martens L, Wiart J. Modeling and Characterization of the Uplink and Downlink Exposure in Wireless Networks. Hindawi International Journal of Antennas and Propagation Volume 2017, Article ID 8243490, 15 pages, 2017.

Kühn S and Kuster N. Field Evaluation of the Human Exposure From Multiband, Multisystem Mobile Phones. IEEE Trans on EMC 55(2):275-287, 2013a.

Kühn S, Kelsh MA, Kuster N, Sheppard AR, Shum M. Analysis of Mobile Phone Design Features Affecting Radiofrequency Power Absorbed in a Human Head Phantom. Bioelectromagnetics 34(6):479-88, $2013 \mathrm{~b}$.

Lauer O, Frei P, Gosselin MC, Joseph W, Röösli M, Fröhlich J. Combining Near- and FarField Exposure for an Organ-Specific and Whole-Body RF-EMF Proxy for Epidemiological Research: A Reference Case. Bioelectromagnetics 34 : 366-374, 2013.

Li CH, Douglas M, Ofli E, Chavannes N, Balzano Q, Kuster N. Mechanisms of RF Electromagnetic Field Absorption in Human Hands and Fingers. IEEE Trans MTT 60(7): 2267-2276, 2012. 
Mills, JH, Adkins WY, Gilbert RM. "Temporary Threshold Shifts Produced by Wideband Noise." The Journal of the Acoustical Society of America 70 (2). ASA: 390-96, 1981. Reverberation on Speech Recognition Performance of Normal-Hearing Children and Adults." Ear and Hearing 31 (3). LWW: 336-44, 2010.

Panda N K, Modi R, Munjal S, Virk RS. "Auditory Changes in Mobile Users: Is Evidence Forthcoming?" Otolaryngology-Head and Neck Surgery 144 (4). SAGE Publications Sage CA: Los Angeles, CA: 581-85, 2011.

Patel H, and Qureshi R. Effects of long term use of mobile phones on hearing status of healthy individuals compared to infrequent mobile phone users in age group of 15-40 years. International journal of research and science, 2013.

Persson T, Törnevik C, Larsson LE, Lovén J. Output Power Distributions of Terminals in a 3G Mobile Communication Network. Bioelectromagnetics 33:320-325, 2012.

Porter SJ, Capstick MH, Faraci F, Flintoft ID, Marvin AC. SAR and Induced Current Measurements on Wired Hands-Free Mobile Telephones. IEEE Technical Seminar on Antenna Measurements and SAR, University of Loughborough. pp 9-13, 2004.

Porter SJ, Capstick MH, Faraci F, Flintoft ID. SAR Testing of Hands-free Mobile Telephones. Mobile Telecomminications and Health Research Programme Report. Project Reference DTi, 30 October 2003.

Robinson, DW, and RS Dadson. 1957. "Threshold of Hearing and Equal-Loudness Relations for Pure Tones, and the Loudness Function." The Journal of the Acoustical Society of America 29 (12). ASA: 1284-8.

Roser K, Schoeni A, Bürgi A, Röösli M. Development of an RF-EMF Exposure Surrogate for Epidemiologic Research. Int. J. Environ. Res. Public Health 12: 5634-5656, 2015.

Roser, K., Schoeni, A., and Röösli, M. (2016). Mobile phone use, behavioural problems and concentration capacity in adolescents: A prospective study. Int. J. Hyg. Environ. Health 219, 759-769.

Sagiv D, Migirov L, Madgar O, Nakache G, Wolf M, Shapira Y. "Mobile Phone Usage Does Not Affect Sudden Sensorineural Hearing Loss." The Journal of Laryngology \& Otology 132 (1). Cambridge University Press: 29-32, 2018.

Schoeni, A., Roser, K., and Röösli, M. (2015). Memory performance, wireless communication and exposure to radiofrequency electromagnetic fields: A prospective cohort study in adolescents. Environ. Int. 85, 343-351.

Siegbahn M, Bit-Babik G, Keshvari J, Christ A, Derat B, Monehbhurrun, Penney C, Vogel M, Wittig T. An International Interlaboratory Comparison of Mobile Phone SAR Calculation With CAD-Based Models. IEEE Trans EMC 52(4): 804-811, 2010.

Smits C and Houtgast T. Results from the Dutch Speech-in-Noise screening test by telephone. Ear and Hearing 2004.

Thielens A, Vermeeren G, Joseph W, Martens L. Stochastic Method for Determination of the Organ-Specific Averaged SAR in Realistic Environments at $950 \mathrm{MHz}$. Bioelectromagnetics, 34(7): 549-562, 2013.

Varsier N, Plets D, Corre Y, Vermeeren G, Joseph W, Aerts S, Martens L, Wiart J. A Novel Method to Assess Human Population Exposure Induced by a Wireless Cellular Network. Bioelectromagnetics 36:451-463, 2015.

Vrijheid M, Mann S, Vecchia P, Wiart J, Taki M, Ardoino L, Armstrong BK, Auvinen A, Bédard D, Berg-Beckhoff G, Brown J, Chetrit A, Collatz-Christensen H, Combalot E, Cook A, Deltour I, Feychting M, Giles G, Hepworth S, Hours M, Iavarone I, Johansen C, Krewski D, Kurttio P, Lagorio S, Lönn S, McBride M, Montestrucq L, Parslow RC, Sadetzki S, Schüz J, Tynes T, Woodward A, Cardis E. 2009. Determinants of mobile phone output power in a multinational study: implications for 
exposure assessment. Occup. Environ. Med. 66:664-71.

http://www.ncbi.nlm.nih.gov/pubmed/19465409.

Wiart J, Dale C, Bosisio AV, Le Cornec A. Analysis of the influence of power control and discontinuous transmission on RF exposure with GSM mobile phones. IEEE Trans Electromag Compatibility 42: 376-38, 2000.

Wouters J, Damman W, Bosman AJ. "Vlaamse opname van woordenlijsten voor spraakaudiometrie.[FLemish recordings for word lists for speech audiometry]" Logopedie: informatiemedium van de Vlaamse vereniging voor logopedisten 7.6: 28 34, 1994. 
Table 1. Simulation results of $S A R_{\text {brain }}$ for an input power of $1 \mathrm{~W}$ into one of the dipoles used to model the mobile phone. The configuration of the simulations is shown in Figure 2.

\begin{tabular}{|c|c|c|}
\hline & \multicolumn{2}{|c|}{$\mathbf{S A R}_{\text {brain }}(\mathbf{W} / \mathbf{k g})$} \\
\hline & $897 \mathrm{MHz}$ & $1800 \mathrm{MHz}$ \\
\hline At Ear & 0.132 & 0.233 \\
\hline Headset and Speaker & $1.4 \times 10-3$ & $6.65 \times 10-4$ \\
\hline
\end{tabular}




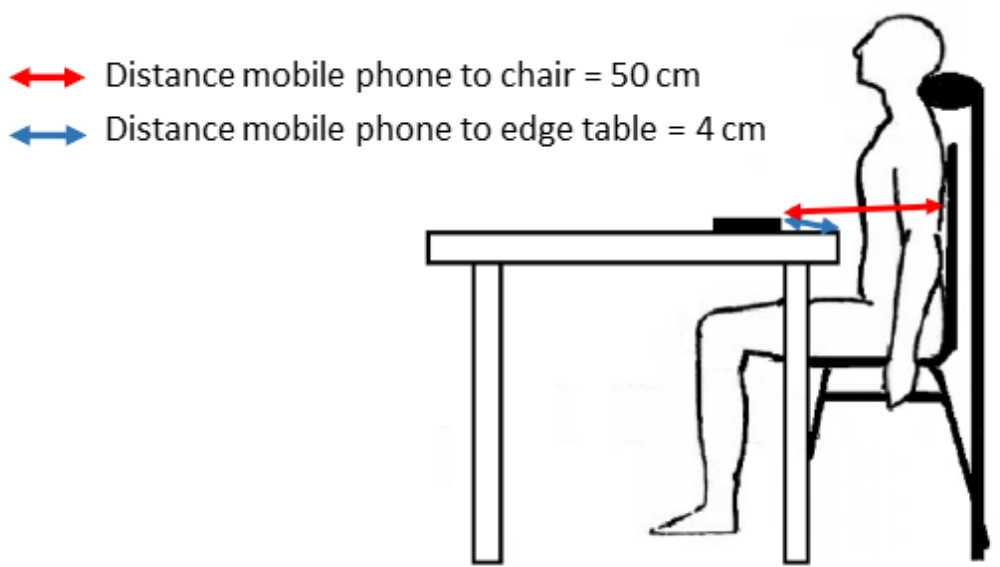

Figure 1. Illustration of the exposure set up.

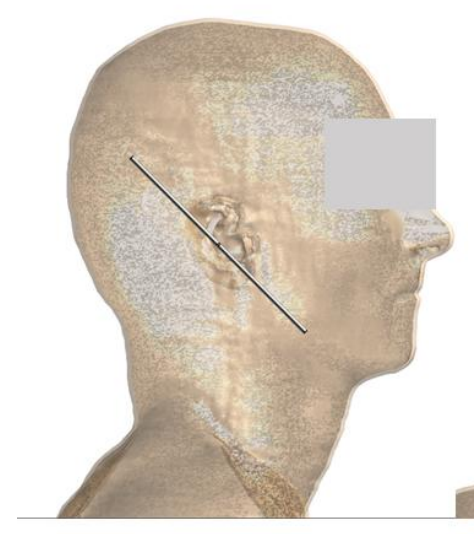

(a)

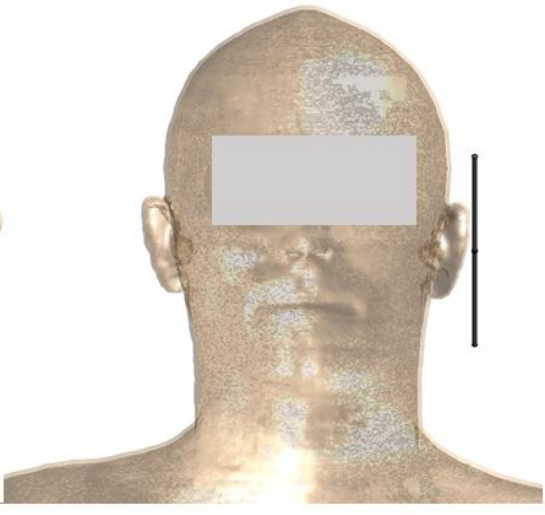

(b)

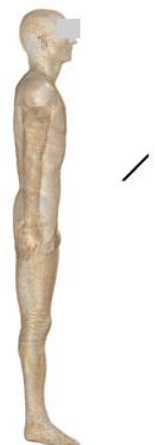

(c)

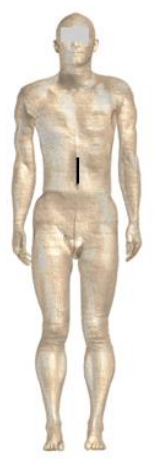

(d)

Figure 2. Simulation setup using the Duke phantom (Gosselin et al., 2014) in two configurations: (a) and (b) show the 'At Ear' configuration from a right and front view, respectively, while (c) and (d) show the simulations used to model the 'Speaker' and 'Headset' exposure conditions for a right and front view respectively. The shown dipole antenna (grey) resonates around $897 \mathrm{MHz}$. 


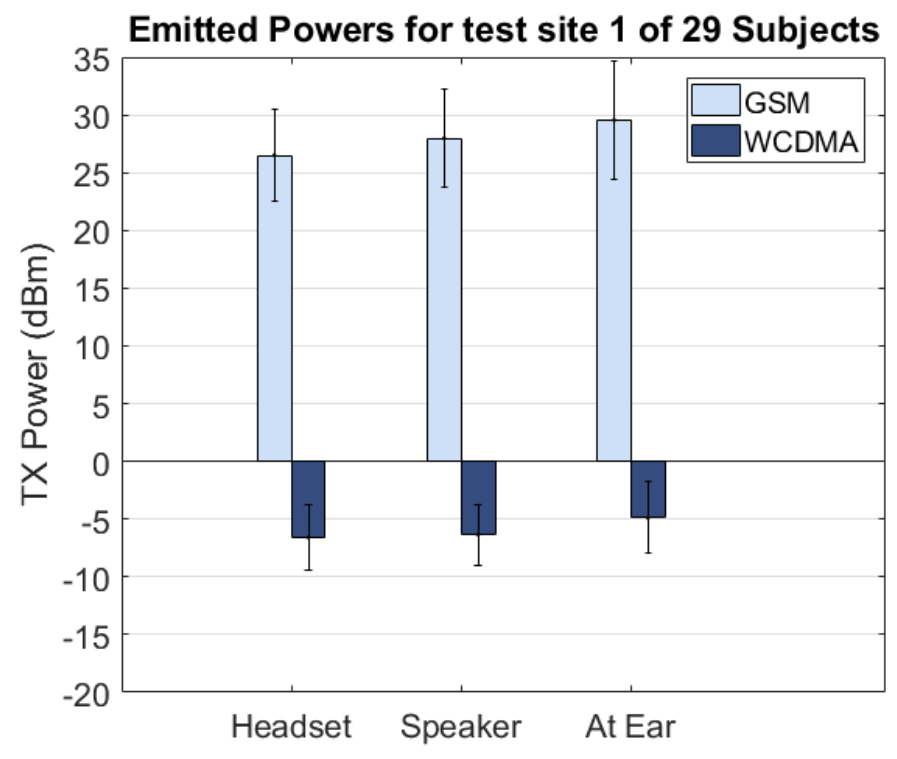

(a)

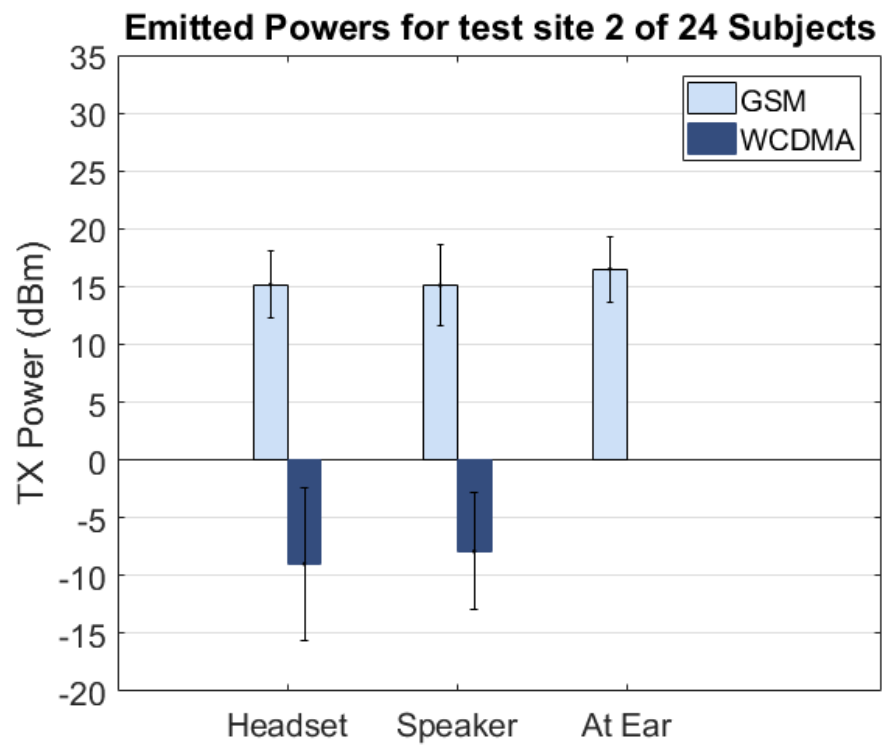

(b)

Figure 3: Emitted RF powers in three exposure conditions for (a) test site 1 and (b) test site 2. The bars indicate the geometric average TX powers, while the whiskers indicate the standard deviations on those averages. 


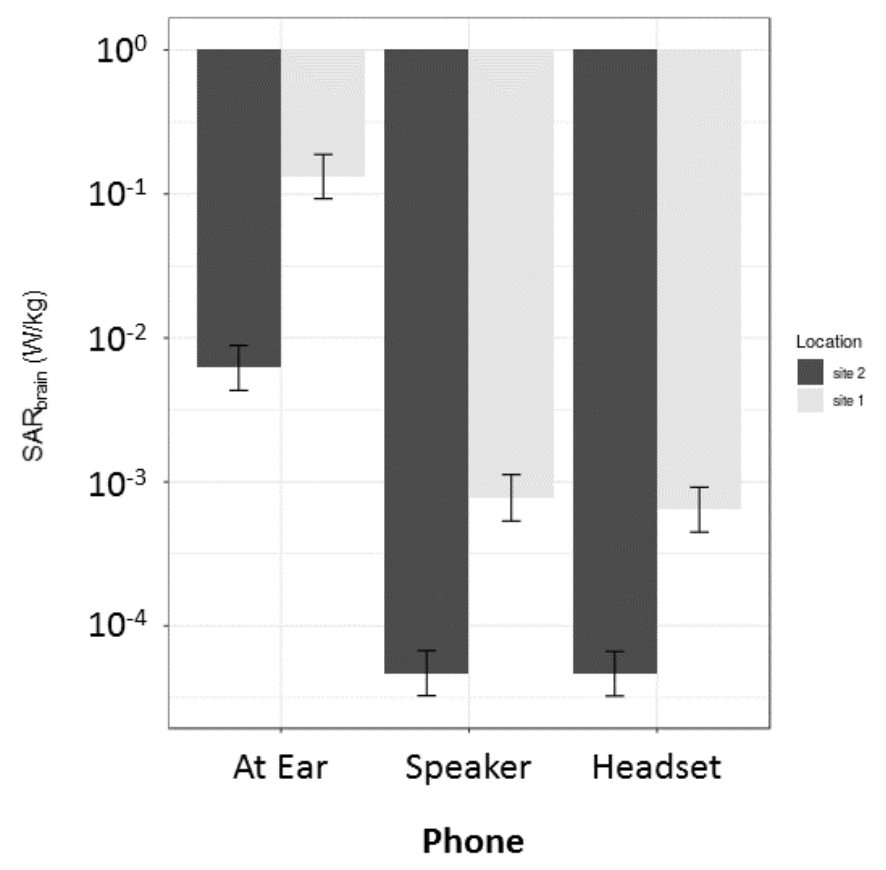

Figure 4: Predicted mean SAR brain values for GSM calls (900 and $1800 \mathrm{MHz}$ ) in three exposure conditions on two test sites (29 subjects on site 1 and 24 subjects on site 2).The error bars depict the $95 \%$ confidence intervals.

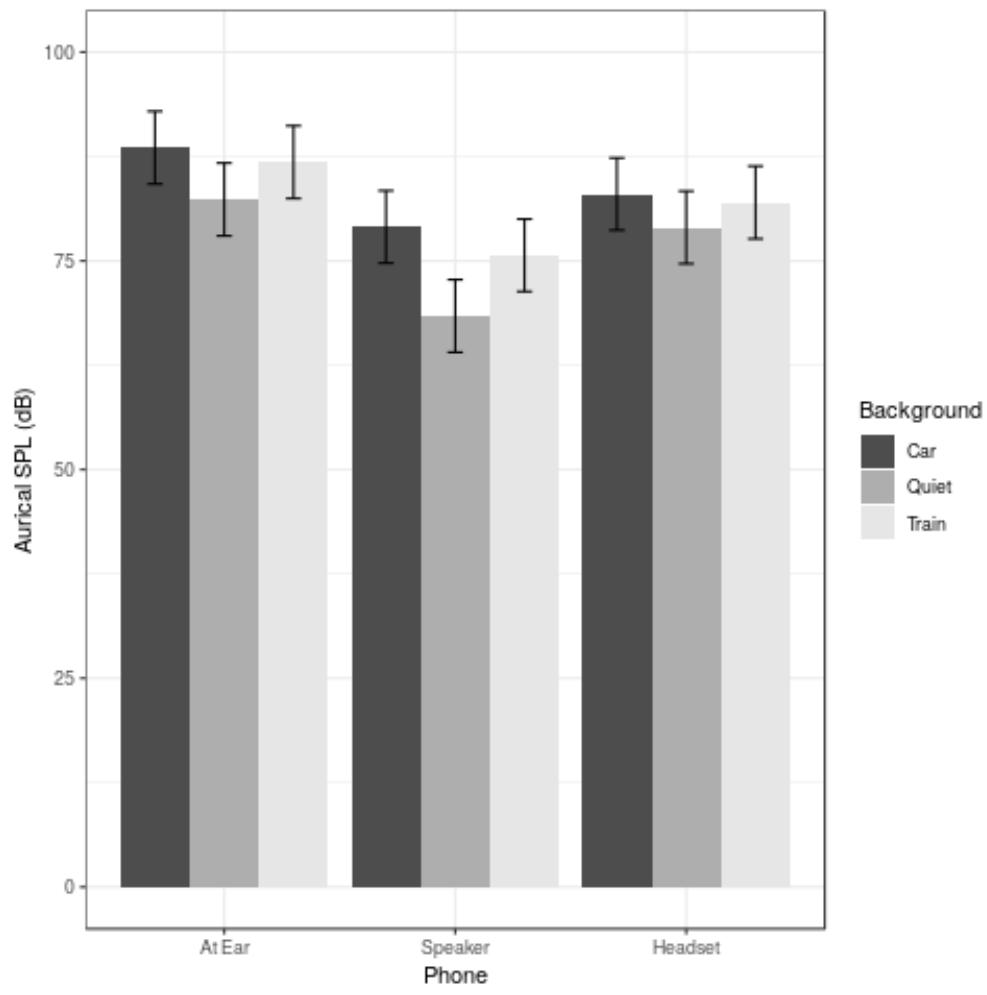

Figure 5: Mean sound pressure measured by the Aurical microphone as a function of background condition and position of the phone. Error bars span the $95 \%$ confidence interval. 


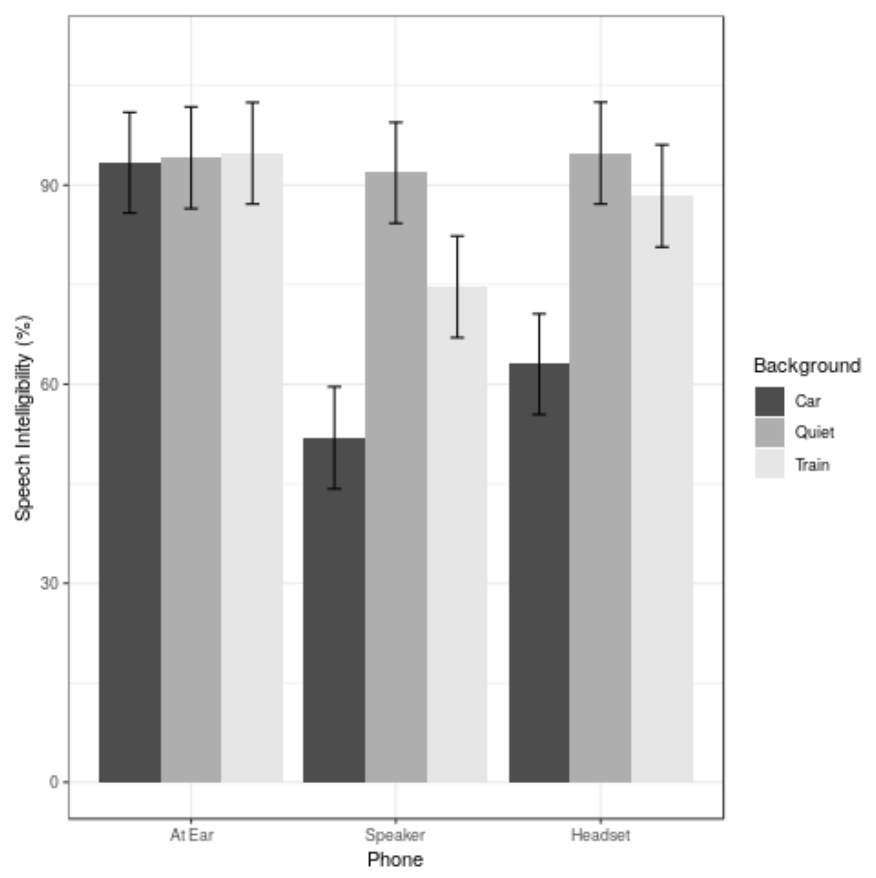

Figure 6: Mean speech intelligibility score (\%) as a function of position of the cell phone and background noise conditions. Error bars span the $95 \%$ confidence interval.

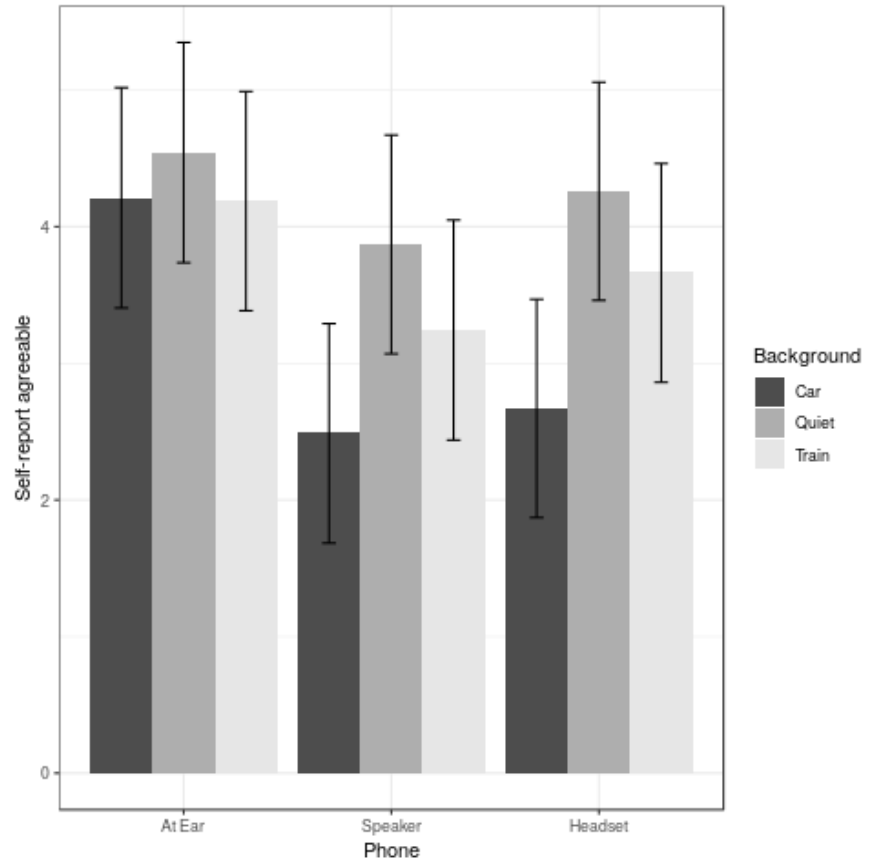

Figure 7: Mean rating of agreeability of listening to speech as a function of position of the cell phone and background noise condition. The error bars depict the $95 \%$ confidence interval. 